$\sqrt{6}$

EDITOR'S

CHOICE

\title{
Effect of weight loss on upper airway size and facial fat in men with obstructive sleep apnoea
}

\author{
Kate Sutherland ${ }^{1,2}$ Richard W W Lee, ${ }^{1,2}$ Craig L Phillips, ${ }^{1,2}$ George Dungan, ${ }^{1}$ \\ Brendon J Yee, ${ }^{1,3}$ John S Magnussen, ${ }^{4}$ Ronald R Grunstein, ${ }^{1,3}$ Peter A Cistulli, ${ }^{1,2}$
}

- Additional materials are published online only. To view these files please visit the journal online (http://thorax.bmj. com).

${ }^{1}$ NHMRC Centre for Sleep Health (CIRUS), Woolcock Institute of Medical Research, University of Sydney, Sydney, Australia

${ }^{2}$ Centre for Sleep Health and Research, Department of Respiratory Medicine, Royal North Shore Hospital, Sydney, Australia

${ }^{3}$ Department of Respiratory and Sleep Medicine, Royal Prince Alfred Hospital, Sydney, Australia

${ }^{4}$ Department of Radiology, Royal Prince Alfred Hospital, Sydney, Australia

\section{Correspondence to}

Dr Peter Cistulli, Centre for Sleep Health and Research, Department of Respiratory Medicine, Level 8, Main Block, Royal North Shore Hospital, Pacific Highway, St Leonards, NSW 2065, Australia; peter.cistulli@sydney.edu.au

Received 12 October 2010 Accepted 12 May 2011 Published Online First 15 June 2011

\section{ABSTRACT}

Background Obstructive sleep apnoea (OSA) is commonly associated with obesity and can be improved by weight loss. Changes in upper airway size related to regional fat loss may mediate the improvement in OSA. This study aimed to assess changes in upper airway size and regional facial and abdominal fat with weight loss and their association with OSA improvement.

Methods Middle-aged obese men with moderate-tosevere OSA underwent a 24-week sibutramine-assisted weight loss trial. Polysomnography and CT of the head and neck were performed at baseline and 24 weeks. The upper airway lumen and facial and parapharyngeal fat were measured with image analysis software.

Results Post-intervention there was a significant reduction in weight $(-7.8 \pm 4.2 \mathrm{~kg}, \mathrm{p}<0.001)$ and apnoea-hypopnoea index (AHI) $(-15.9 \pm 20.5$ events/h, $\mathrm{p}<0.001)$. Velopharyngeal airway volume significantly increased from baseline $\left(5.3 \pm 0.4\right.$ to $6.3 \pm 0.3 \mathrm{~cm}^{3}$, $\mathrm{p}<0.01)$ and facial and paraphayngeal fat volume significantly reduced. A reduction in upper airway length was associated with improvement in $\mathrm{AHI}(\mathrm{r}=0.385$, $p=0.005$ ). The variance in $\mathrm{AHI}$ improvement was best explained by changes in upper airway length and visceral abdominal fat $\left(R^{2}=0.31, p=0.004\right)$.

Conclusions Weight loss increases velopharyngeal airway volume, but changes in upper airway length appear to have a greater influence on the reduction in apnoea frequency. Inter-individual variability in the effects of weight loss on OSA severity cannot be explained in terms of changes in upper airway structure and local fat deposition alone.

\section{INTRODUCTION}

Obesity is the most common known risk factor for obstructive sleep apnoea (OSA) and is identifiable in at least $50 \%$ of adults with the disorder. ${ }^{1}$ Obesity is unique among other major risk factors (eg, age, male gender, postmenopausal status, craniofacial morphology) in that it is reversible and therefore represents a target for treatment. Indeed, weight loss - through lifestyle, surgical or pharmacological manipulations-improves OSA. ${ }^{2-4}$

The exact mechanisms by which obesity contributes to upper airway collapse during sleep are not completely understood. Increased local fat deposition presumably compromises airway space, while abdominal obesity reduces lung volume and therefore caudal traction on the pharynx. ${ }^{5}$ Although weight loss reduces OSA severity, it does not necessarily resolve and there is substantial individual variability in the impact of weight loss

\section{Key messages}

What is the key question?

- Does improvement in OSA with weight loss reflect an increased upper airway size related to regional fat loss?

What is the bottom line?

- Velopharyngeal volume increased slightly in obese men with OSA after a 6-month weight loss programme; however, change in airway length and visceral abdominal fat were the only measured variables to relate to OSA improvement.

\section{Why read on?}

- This is the largest published study to date to explore the relationship between weight loss and improvement in OSA in terms of changes in upper airway structure and regional fat deposition.

on OSA. ${ }^{34}$ It is likely that other factors, rather than total weight reduction, may be more closely linked to the outcome of weight loss. An anatomically smaller pharyngeal airway has been identified in patients with $\mathrm{OSA}^{6}$ and may result from enlargement of surrounding soft tissues, reduced craniofacial skeleton or a combination of both. ${ }^{7}$ Other OSA treatments (eg, positive pressure therapy and oral appliance therapy) increase upper airway volume. ${ }^{8} 9$ Weight loss in non-apnoeic women has been reported to increase upper airway size $^{6}$; however, the effect of weight loss on upper airway structure in OSA has received little attention to date. Two previous studies have reported no changes in pharyngeal cross-sectional area (CSA) after weight loss; however, these studies were small in sample size. ${ }^{10} 11$

Regional fat may play an important role in the improvement in OSA subsequent to weight loss. Visceral abdominal fat is reported to be most closely associated with OSA, ${ }^{12}$ and buccal fat (chubby cheeks) has been shown to correlate with visceral fat and may be equally metabolically active. ${ }^{13} 14$ We have previously shown that surface face width is greater in patients with OSA than in non-OSA controls, and that this measurement relates strongly to measures of obesity (eg, neck and waist circumference). ${ }^{15}$ Furthermore, this surface facial metric is more important than other known anthropometric and craniofacial risk factors in predicting OSA. ${ }^{16}$

The aims of this study were to assess the effects of weight loss on the upper airway and surrounding 
regional facial fat in obese men with OSA and to assess the relationship between these changes and changes in general obesity and OSA severity. We hypothesised that improved sleep apnoea after weight loss would be associated with an increase in airway dimensions related to facial fat loss, and also that facial fat loss would be closely related to changes in visceral abdominal volume.

\section{METHODS}

\section{Subjects}

The study subjects were a subset of those in a 24 -week sibutramine-assisted weight loss study ${ }^{4} 17$ who additionally underwent upper airway and abdominal imaging. Inclusion criteria were men with OSA aged $30-70$ years, body mass index $\geq 30 \mathrm{~kg} / \mathrm{m}^{2}$, apnoea-hypopnoea index (AHI) $\geq 15$ events/h and an Epworth Sleepiness Scale score $>10$ (see online supplement).

\section{Weight loss and polysomnography}

Subjects were treated with sibutramine (serotonin and norepinephrine reuptake inhibitor, 10 or $15 \mathrm{mg}$ daily) and followed a $2500 \mathrm{~kJ}$ daily deficit diet with exercise advice for 24 weeks. ${ }^{4}$ Anthropometric data (height, weight, neck and waist circumference) were collected and standard polysomnography (Compumedics, Melbourne, Australia) was performed at baseline and 24 weeks. ${ }^{4} 17$

\section{Computed tomography}

Patients underwent a low-dose CT scan of the upper airway and abdomen using a 16-slice scanner (GE Medical Systems, Milwaukee, USA) (see online supplement for additional details).

\section{CT image analysis}

CT images for upper airway and facial fat analysis were processed using image analysis software (Amira 4.1; Visage Imaging Inc, Carlsbad, California, USA). CT images were automatically segmented based on Hounsfield unit (HU) values $^{18}$ (figure 1C; see online supplement for additional details).

Upper airway regions were defined as velopharynx (hard palate to uvula tip), oropharynx (uvula tip to epiglottis base) and hypopharynx (epiglottis tip to vocal fold) (figure 1A). Upper airway length was calculated as the sum of the thickness of airway axial slices (figure 1A). Anteroposterior (A-P) and lateral (L) diameters were obtained for the velopharynx and oropharynx on the axial slice at the midpoint of the region.
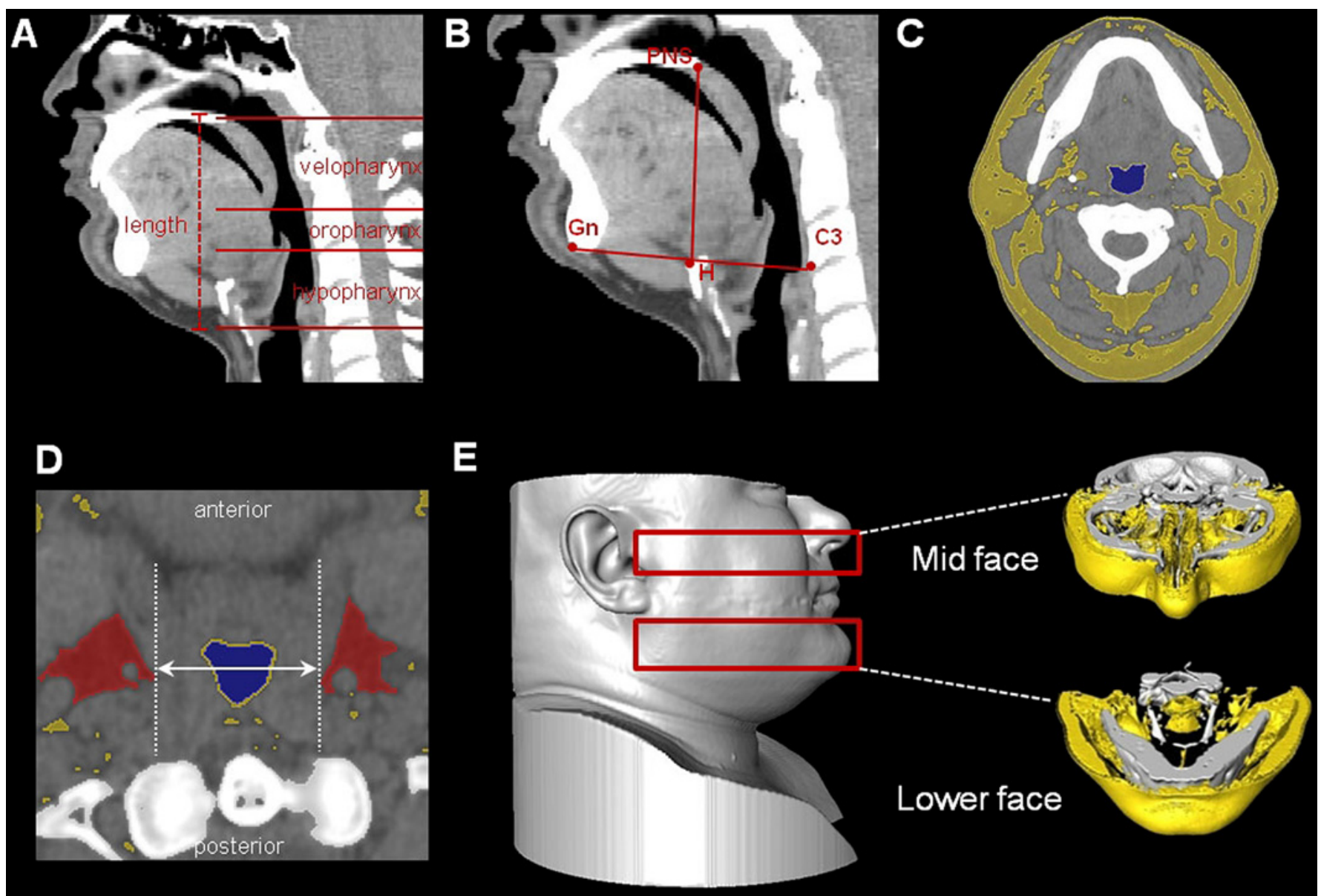

Figure 1 CT image analysis. (A) Mid-sagittal representation of the velopharyngeal, oropharyngeal and hypopharyngeal upper airway regions. Airway length was calculated as the sum of the thickness of the total number of image slices in the upper airway. (B) Hyoid bone position was determined on the mid-sagittal slice by the measurement of three linear distances between the hyoid $(\mathrm{H})$ and C3 (C3 vertabrae), $\mathrm{H}$ and posterior nasal spine (PNS), and $\mathrm{H}$ and gnathion (Gn). (C) Representative axial CT slice illustrating segmentation of fat (yellow), upper airway lumen (blue) and bone (white) based on the Hounsfield scale where individual voxels are assigned to a tissue category based on their CT value. (D) The parapharyngeal fat pads were segmented separately (red). A measure of fat pad distance was made on axial slices by the length of a horizontal line spanning the distance between two vertical lines (anteroposterior direction) drawn along the medial borders of the fat pads. (E) Surface reconstruction of CT scan of the head depicting the mid and lower facial regions analysed (red rectangles). Corresponding three-dimensional reconstructions of internal fat volume (yellow) and bone (white) in the analysed regions (frontal view). 
Fat volume was measured in two defined regions of the face: mid-face and lower face. Facial regions and fat volumes measured are depicted in figure $1 \mathrm{E}$. Bone volume in these regions was also recorded for methodology validation. The parapharyngeal fat pads were segmented separately for volume calculation. The distance between the fat pads was measured on the axial slice that intersected in the middle of the fat pads as shown in figure $1 \mathrm{D} .{ }^{19}$

Hyoid position was measured on the mid-sagittal slice by three linear distances between the anterosuperior point of the hyoid $(\mathrm{H})$ and three other points: posterior nasal spine (PNS), gnathion $(\mathrm{Gn})$ and the anteroinferior point of the C3 vertebrae (C3) (figure 1B).

Abdominal subcutaneous and visceral adipose tissue (SCAT and VAT) volume analysis has been previously described. ${ }^{17}$ Additional details of imaging and analyses are given in the online supplement.

\section{Statistical analysis}

Statistical analyses were performed using statistical software package SPSS Version 17.0 for Windows (SPSS Inc). AHI, anthropometric and CT-measured variables (upper airway and fat) were compared between baseline and 24 weeks using paired $t$ tests or Wilcoxon signed-rank tests, depending on data distribution. Correlation (Pearson $r$ or Spearman $\rho$ depending on the distribution of the data) was used to explore associations between continuous variables in all patients. Correlation analysis was used to assess relationships between (1) changes in OSA and upper airway and fat; (2) changes in anthropometric measures and fat volumes; (3) changes in facial and abdominal fat; and (4) changes in facial fat and upper airway dimensions. To account for multiple comparisons, an adjusted $p$ value of $<0.01$ was considered statistically significant for the correlation analyses. Multivariate forward linear regression was used to investigate the relationship between improved sleep apnoea $(\% \Delta$ AHI, dependent variable) and changes in fat and airway and anthropometric variables (independent variables). Variables selected for consideration in the model were those that in correlation analysis had $p$ values $<0.1$. Change in supine sleep time was also considered as an independent variable to ensure that differences in body position between sleep studies did not contribute to changes in AHI. Multivariate linear regression was also used to assess whether baseline CT-measured variables could predict the amount of improvement in AHI. All independent variables in the regression analysis were examined for colinearity and analysed in separate models if necessary. The models were checked to ensure the assumptions of no multicolinearity, linearity and homoscedasticity were met. Statistical significance was accepted at $p<0.05$

\section{RESULTS}

\section{Subject characteristics}

The study subjects were Caucasian men aged $46.6 \pm 9.8$ years who were moderately obese $\left(34.1 \pm 2.6 \mathrm{~kg} / \mathrm{m}^{2}\right)$ with moderateto-severe OSA (AHI range 16.9-109.9 events/h). The subjects had moderate weight loss $(7.8 \pm 4.2 \mathrm{~kg})$ and improvement in OSA (31\% reduction in $\mathrm{AHI})$, although with large individual variation (see figure S1 in online data supplement).

\section{Anthropometric, fat and upper airway variables before and after weight loss}

Paired CT data (baseline and 24 weeks) were analysed for 54 subjects. Comparative anthropometric, upper airway, regional fat and hyoid position data between the two time points are presented in table 1 .

Upper airway length and oropharyngeal or hypopharyngeal measurements did not change. Velopharyngeal volume increased significantly at 24 weeks $\left(5.3 \pm 2.6 \mathrm{~cm}^{3}\right.$ vs $6.3 \pm 2.4 \mathrm{~cm}^{3}$; figure 2) along with minimum CSA, mean CSA and the lateral diameter.

Facial (mid, lower face, fat pad) and abdominal (subcutaneous and visceral) fat volumes decreased following weight loss. Bone volume did not change between analysed scans in either face regions (data not shown), validating this methodology to measure changes in facial fat volume reliably. The parapharyngeal fat pad volume decreased significantly and fat pad distance increased slightly but without reaching statistical significance. Surface reconstructions from CT images of the face and upper airway before and after weight loss are shown for an individual patient (figure 3).

Hyoid to PNS and hyoid to C3 distances decreased, suggesting there was posterior and superior movement of the hyoid bone with weight loss.

\section{Relationships between changes in anthropometric and CT-measured variables (upper airway and facial and abdominal fat) and OSA improvement}

Anthropometric changes showed some relationship with improvement in AHI (table 2), but these correlations did not reach statistical significance. Changes in facial and parapharyngeal fat did not correlate with AHI. Abdominal fat changes showed some relationship with changes in AHI, but only changes in visceral abdominal fat significantly correlated with improvement in AHI.

Upper airway structural changes did not show any relationship with AHI improvement. Although there was no mean change in upper airway length between baseline and 24 weeks, there was a positive correlation between percentage change in AHI and difference in upper airway length. Multiple linear regression analysis (table 3) showed that the percentage improvement in AHI was best predicted by a reduction in airway length and visceral abdominal fat. This model explained approximately $30 \%$ of the variance in AHI change. There was colinearity between anthropometric and abdominal fat measures. To account for this, these predictors were considered in separate models. Although weight, waist circumference and subcutaneous abdominal fat were also found to be predictive in combination with change in airway length, these models did not explain as much of the variance in AHI change as the model containing visceral abdominal fat (see table S2 in online data supplement).

\section{Relationships between changes in anthropometric and CT-measured facial and abdominal fat}

Changes in anthropometric measures (weight, neck and waist circumference) were strongly related to changes in facial fat (mid and lower face) and abdominal fat (subcutaneous and visceral) volumes measured by CT (table 4). There was no relationship between changes in fat pad volume and anthropometric measures.

\section{Relationships between facial and abdominal fat loss}

Changes in abdominal fat volumes were strongly related to changes in facial fat volumes but not parapharyngeal fat pad volume (table 5). Generally, facial (mid and lower face) fat loss was more closely related to visceral than to subcutaneous abdominal fat loss. Visceral abdominal fat loss appeared to be more closely related to mid-face fat loss than lower face fat loss. 
Table 1 Paired comparisons of anthropometric and CT-measured variables at baseline and after a 24week weight loss programme

\begin{tabular}{|c|c|c|c|c|}
\hline Variable & $\mathbf{N}$ & Baseline & 24 weeks & p Value \\
\hline AHI (events/h)* & 54 & $41.0(27.2-56.3)$ & $26.1(14.9-38.0)$ & $<0.001$ \\
\hline \multicolumn{5}{|l|}{ Anthropometry } \\
\hline Weight $(\mathrm{kg})$ & 54 & $107.5 \pm 11.8$ & $99.7 \pm 12.6$ & $<0.001$ \\
\hline Neck circumference $(\mathrm{cm})$ & 54 & $44.6 \pm 2.4$ & $43.2 \pm 2.5$ & $<0.001$ \\
\hline Waist circumference $(\mathrm{cm})$ & 53 & $116.0 \pm 8.1$ & $108.0 \pm 9.2$ & $<0.001$ \\
\hline \multicolumn{5}{|l|}{ Upper airway } \\
\hline Length $(\mathrm{cm})$ & 51 & $10.0 \pm 0.8$ & $9.9 \pm 0.8$ & 0.325 \\
\hline Volume $\left(\mathrm{cm}^{3}\right)$ & 51 & $18.8 \pm 5.7$ & $19.7 \pm 6.0$ & 0.224 \\
\hline \multicolumn{5}{|l|}{ Velopharynx } \\
\hline Minimum CSA $\left(\mathrm{cm}^{2}\right)^{*}$ & 51 & $0.7(0.4-0.9)$ & $0.8(0.5-1.0)$ & 0.033 \\
\hline Mean CSA $\left(\mathrm{cm}^{2}\right)^{*}$ & 51 & $1.4(1.0-1.7)$ & $1.7(1.4-2.1)$ & 0.002 \\
\hline Lateral diameter $(\mathrm{cm})$ & 48 & $1.5 \pm 0.5$ & $1.7 \pm 0.5$ & 0.009 \\
\hline AP diameter $(\mathrm{cm})$ & 48 & $0.8 \pm 0.3$ & $0.9 \pm 0.2$ & 0.125 \\
\hline \multicolumn{5}{|l|}{ Oropharynx } \\
\hline Minimum CSA $\left(\mathrm{cm}^{2}\right)^{*}$ & 51 & $1.1(0.7-1.7)$ & $1.1(0.7-1.5)$ & 0.978 \\
\hline Mean CSA $\left(\mathrm{cm}^{2}\right)^{*}$ & 51 & $2.2(1.7-2.8)$ & $2.1(1.5-2.7)$ & 0.494 \\
\hline Lateral diameter $(\mathrm{cm})$ & 50 & $2.4 \pm 0.7$ & $2.2 \pm 0.8$ & 0.220 \\
\hline AP diameter $(\mathrm{cm})$ & 50 & $1.4 \pm 0.5$ & $1.3 \pm 0.5$ & 0.057 \\
\hline \multicolumn{5}{|l|}{ Hypopharynx } \\
\hline Minimum CSA $\left(\mathrm{cm}^{2}\right)^{*}$ & 51 & $1.0(0.6-1.4)$ & $1.0(0.5-1.3)$ & 0.763 \\
\hline Mean CSA $\left(\mathrm{cm}^{2}\right)^{*}$ & 51 & $1.9(1.4-2.3)$ & $1.9(1.5-2.4)$ & 0.512 \\
\hline \multicolumn{5}{|l|}{ Regional fat } \\
\hline Mid-face fat volume $\left(\mathrm{cm}^{3}\right)$ & 47 & $86.1 \pm 17.1$ & $78.3 \pm 15.8$ & $<0.001$ \\
\hline Lower face fat volume $\left(\mathrm{cm}^{3}\right)$ & 47 & $97.8 \pm 34.8$ & $89.5 \pm 32.6$ & $<0.001$ \\
\hline Fat pad volume $\left(\mathrm{cm}^{3}\right)^{*}$ & 42 & $3.5(2.3-5.0)$ & $2.9(2.7-4.4)$ & $<0.001$ \\
\hline Fat pad distance $(\mathrm{cm})$ & 42 & $3.7 \pm 0.6$ & $3.8 \pm 0.6$ & 0.082 \\
\hline VAT $\left(\mathrm{cm}^{3}\right)$ & 52 & $142.9 \pm 36.5$ & $117.0 \pm 37.2$ & $<0.001$ \\
\hline $\operatorname{SCAT}\left(\mathrm{cm}^{3}\right)$ & 51 & $216.4 \pm 53.8$ & $184.8 \pm 52.5$ & $<0.001$ \\
\hline \multicolumn{5}{|l|}{ Hyoid position } \\
\hline $\mathrm{H}-\mathrm{PNS}$ distance $(\mathrm{cm})$ & 54 & $7.5 \pm 0.8$ & $7.4 \pm 0.8$ & 0.009 \\
\hline $\mathrm{H}-\mathrm{Gn}$ distance $(\mathrm{cm})$ & 53 & $5.0 \pm 0.5$ & $5.0 \pm 0.5$ & 0.222 \\
\hline $\mathrm{H}-\mathrm{C} 3$ distance $(\mathrm{cm})$ & 54 & $4.3 \pm 0.5$ & $4.2 \pm 0.5$ & 0.021 \\
\hline
\end{tabular}

*Data are presented as mean $\pm S D$ or median (IOR) where data were not normally distributed and non-parametric tests were used. $\mathrm{AP}$, anteroposterior diameter; AHI, apnoea-hypopnoea index; C3, C3 vertebrae; CSA, cross-sectional area; Gn, gnathion; $\mathrm{H}$, hyoid; $\mathrm{L}$, lateral diameter; PNS, posterior nasal spine; SCAT, abdominal subcutaneous adipose tissue; VAT, abdominal visceral adipose tissue.

\section{Relationships between fat loss and upper airway changes}

Facial or parapharyngeal fat loss was not associated with changes in the upper airway. No anthropometric measures or abdominal fat volumes correlated with changes in upper airway variables.

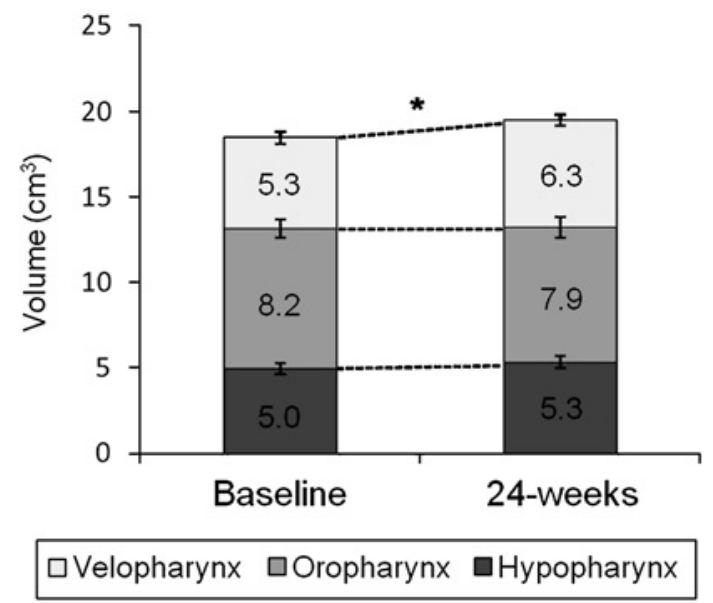

Figure 2 Upper airway volumes at baseline and after a 24-week weight loss programme. The velopharyngeal volume increased compared with baseline $\left(5.3 \pm 2.6 \mathrm{~cm}^{3}\right.$ vs $\left.6.3 \pm 2.4 \mathrm{~cm}^{3}\right)$. There was no change in oropharynx or hypopharynx volume $(\mathrm{N}=51)$. ${ }^{*} \mathrm{p}<0.01$.

\section{Baseline measurements and improvement in OSA}

Baseline CT variables were checked for relationships with improvement in AHI to assess any predictive value for weight loss outcome. No baseline measures correlated with or were predictive of the amount of improvement seen in AHI after weight loss.

\section{DISCUSSION}

Weight loss decreases upper airway collapsibility during sleep, and this improved upper airway function can be attributed to reduced mechanical loads resulting from adiposity and/or subsequent improvements in neuromuscular control. However, the effect of weight loss on upper airway structure in OSA has received little attention in the literature. To our knowledge, this is the largest study to investigate the effects of weight loss on the upper airway and regional facial fat in obese men with OSA using volumetric analyses. Weight loss was associated with an increase in velopharyngeal airway size and reductions in facial and parapharyngeal fat volume.

\section{Upper airway}

Increased extraluminal tissue pressure and reduced airway space resulting from fat deposition around the pharynx can facilitate upper airway collapse. ${ }^{5}$ We have shown enlargement of the velopharyngeal airway space in obese men with apnoea after weight loss. The velopharyngeal walls are directly bordered by 


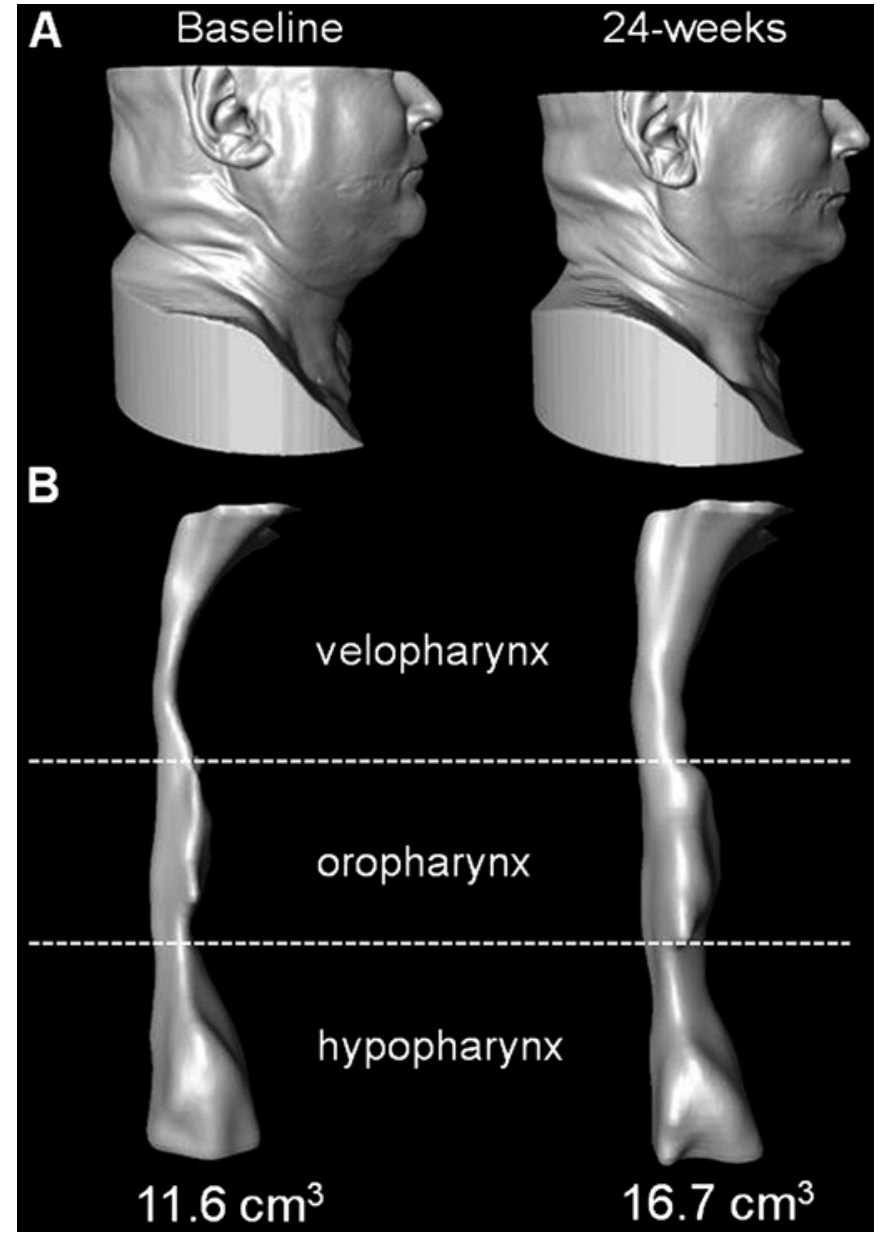

Figure 3 Surface reconstructions from CT scans of a single patient before and after weight loss showing $(A)$ head and neck region and $(B)$ the upper airway. The patient showed a $5.1 \mathrm{~cm}^{3}$ increase in upper airway volume after $19 \mathrm{~kg}$ weight loss (approximately $18 \%$ of body weight) associated with an improvement in apnoea-hypopnoea index (AHI) from 55.9 events/h to 15.1 events/h.

the lateral parapharyngeal fat pads. Reduced volume of these adipose tissue structures with fat loss could alter traction on surrounding soft tissues and influence velopharyngeal size, particularly in the lateral dimension (as found in this study). The only previous investigations of the effects of weight loss on upper airway structure in OSA have reported no changes in pharyngeal areas following weight loss. ${ }^{10}{ }^{11}$ However, this may reflect the smaller sample sizes $(n=12)$, analysis being limited to CSA and gender differences, with one sample predominantly female. ${ }^{10}$ Although we did not investigate other upper airway soft tissue structures, a previous weight loss imaging study in women without OSA reported no changes in tongue and soft palate volumes, ${ }^{19}$ which may account for the absence of changes in the lower pharyngeal regions.

Decreased airway length was associated with a greater improvement in the severity of OSA. Length change was found to be more influential than total weight or visceral abdominal fat loss in explaining AHI improvement. A longer upper airway has been associated with $\mathrm{OSA}^{20}$ and may be an important factor in the propensity to collapse. Indeed, a longer airway in men appears to be the primary characteristic-anatomical or functional-to explain the male predisposition to OSA. ${ }^{21}$ Furthermore, pharyngeal length increases in the supine position in men with OSA but not controls. ${ }^{22}$ Our finding may suggest
Table 2 Correlation coefficients for percentage change $(\% \Delta)$ in $\mathrm{AHI}$ with $\% \Delta$ in anthropometric and CT-measured variables

\begin{tabular}{|c|c|c|c|}
\hline \multirow[b]{2}{*}{ Variable } & \multirow[b]{2}{*}{$\mathbf{N}$} & \multicolumn{2}{|l|}{$\% \triangle$ AHI } \\
\hline & & $\bar{R}$ & p Value \\
\hline \multicolumn{4}{|l|}{ Anthropometry } \\
\hline$\% \Delta$ Weight & 54 & $0.334^{*}$ & 0.014 \\
\hline$\% \Delta$ Neck circumference & 53 & 0.265 & 0.055 \\
\hline$\% \Delta$ Waist circumference & 53 & 0.280 & 0.043 \\
\hline \multicolumn{4}{|l|}{ Upper airway } \\
\hline$\% \Delta$ Length & 51 & 0.385 & 0.005 \\
\hline$\% \Delta$ Volume & 51 & 0.115 & 0.423 \\
\hline \multicolumn{4}{|l|}{ Regional fat } \\
\hline$\% \Delta$ Mid-face fat volume & 47 & 0.231 & 0.118 \\
\hline$\% \Delta$ Lower face fat volume & 47 & 0.219 & 0.139 \\
\hline$\% \Delta$ Fat pad volume & 42 & -0.069 & 0.665 \\
\hline$\% \triangle$ VAT & 51 & 0.356 & 0.010 \\
\hline$\% \triangle$ SCAT & 52 & 0.328 & 0.018 \\
\hline
\end{tabular}

*Spearman's $\rho$.

AHI, apnoea-hypopnoea index; R, correlation coefficient; SCAT, abdominal subcutaneous adipose tissue; VAT, abdominal visceral adipose tissue.

that a decrease in supine upper airway length after weight loss contributes to reduced collapsibility. However, the mechanisms by which upper airway length is reduced are unclear. Increased lung volume decreases pharyngeal collapsibility ${ }^{23}$ and increases pharyngeal CSA, ${ }^{24} 25$ presumably via increased caudal traction on upper airway structures from mediastinal, rib cage and cervical strap muscle connections. ${ }^{26}$ Such increases in pharyngeal CSA could be associated with shortening of the total upper airway length, but the effects of lung volume changes on upper airway structure requires further investigation. Similarly, changes in adipose tissue around the pharynx could increase lateral traction, shortening the upper airway.

\section{Hyoid position}

Hyoid position shifted superiorly and posteriorly post-intervention. An inferiorly positioned hyoid bone is a cephalometric finding commonly associated with OSA. ${ }^{27}$ It is unclear whether an inferiorly positioned hyoid is a cause or effect of OSA, but the decreased vertical distance of the hyoid position observed in this study may result from a lessening of downward pressure due to a reduction in excess pharyngeal tissues.

\section{Regional fat}

Fat loss in both facial and abdominal regions correlated highly with anthropometric changes of obesity. In this study, change in visceral adipose tissue volume had the strongest relationship

Table 3 Multiple regression analyses for percentage change $(\% \Delta)$ in $\mathrm{AHI}(\mathrm{N}=48)$

\begin{tabular}{|c|c|c|c|c|}
\hline \multirow[b]{2}{*}{ Variable } & \multirow{2}{*}{$\begin{array}{l}\text { B (\% } \% \Delta \text { AHI per } \\
\text { unit } \% \Delta \text { in } \\
\text { variable) }\end{array}$} & \multicolumn{2}{|c|}{$95 \% \mathrm{Cl}$ for B } & \multirow[b]{2}{*}{ p Value } \\
\hline & & Lower & Upper & \\
\hline \multicolumn{5}{|c|}{ Model 1: $R^{2}=0.165, p=0.004$} \\
\hline$\% \Delta$ Airway length & 2.7 & 0.9 & 4.5 & 0.004 \\
\hline \multicolumn{5}{|c|}{ Model 2: $\mathrm{R}^{2}=0.305, \mathrm{p}=0.004$} \\
\hline$\% \Delta$ Airway length & 2.91 & 1.2 & 4.6 & 0.001 \\
\hline$\% \triangle$ VAT & 0.71 & 0.2 & 1.2 & 0.004 \\
\hline
\end{tabular}

Variables not in equation: $\Delta \%$ supine sleep time, $\% \Delta \mathrm{H}-\mathrm{PNS}, \% \Delta \mathrm{H}-\mathrm{Gn}$.

Colinear variables considered in separate models (see online data supplement): $\% \Delta$ weight, $\% \Delta$ neck circumference, $\% \Delta$ waist circumference, $\% \Delta$ SCAT.

AHI, apnoea-hypopnoea index; B, unstandardised coefficients; VAT, abdominal visceral adipose tissue. 
Table 4 Correlation coefficients for percentage changes $(\% \Delta)$ in anthropometric and CT-measured fat variables

\begin{tabular}{|c|c|c|c|c|c|c|}
\hline \multirow[b]{3}{*}{ CT variables } & \multicolumn{6}{|c|}{ Anthropometric variables } \\
\hline & \multicolumn{2}{|c|}{$\% \Delta$ Weight } & \multicolumn{2}{|l|}{$\% \triangle \mathbf{N C}$} & \multicolumn{2}{|c|}{$\% \triangle$ WC } \\
\hline & $\overline{\mathbf{R}}$ & $\overline{p \text { Value }}$ & $\overline{\mathbf{R}}$ & $\overline{p \text { Value }}$ & $\overline{\mathbf{R}}$ & p Value \\
\hline$\% \Delta$ Lower face fat volume & $0.660^{*}$ & $<0.001$ & 0.408 & 0.005 & 0.748 & $<0.001$ \\
\hline$\% \Delta$ Fat pad volume & 0.324 & 0.036 & $-0.014^{*}$ & 0.931 & $0.216^{*}$ & 0.174 \\
\hline$\% \triangle$ VAT & $0.671^{*}$ & $<0.001$ & $0.274^{*}$ & 0.054 & 0.523 & $<0.001$ \\
\hline
\end{tabular}

${ }^{*}$ Spearman's $\rho$.

$\mathrm{R}$, correlation coefficient; SCAT, abdominal subcutaneous adipose tissue; VAT, abdominal visceral adipose tissue.

with improvement in OSA of all the obesity measures. Changes in facial fat correlated with abdominal fat loss, with this relationship being strongest between visceral adipose tissue and mid-face fat volume. Indeed, reduction in visceral adipose tissue was more closely associated with the amount of mid-face fat loss than changes in the anthropometric measure of waist circumference, and this supports the concept that facial fat may be an important risk factor for OSA. Interestingly, we found that at baseline (before weight loss) the only obesity measures to reflect the amount of visceral abdominal fat were waist circumference and mid-face fat volume, with both correlations being equally strong (see online supplement). This relationship with visceral fat was also preserved for the simplified measure of mid-face width. Our previous work using craniofacial photography identified this surface facial measure as highly predictive of OSA, ${ }^{16}$ and the current study suggests that this simple craniofacial metric may provide an insight into obesity-related risk factors for OSA in regions beyond the face.

Parapharyngeal fat pad size has previously been shown not to relate to the severity of $\operatorname{OSA}^{28} 29$ and was not related to improvement in AHI in the current study. However, our assessments of parapharyngeal and facial fat did not take craniofacial size into consideration. Upper airway collapsibility relates not only to the amount of surrounding tissue but also to the size of the craniofacial skeleton enclosing it, a concept termed 'anatomical balance'. 70 Therefore, changes in total upper airway volume in relation to overall anatomy and not just reduced adipose tissue size may be important. In this study, soft tissue within the craniofacial enclosure could not be assessed due to artefact in the oral region obscuring the tongue. However, a surrogate correction for craniofacial bony enclosure using the bony facial width did not relate our fat volumes more closely to OSA (results not shown). Craniofacial size may be important as a denominator in assessing regional fat loss effects on OSA but requires verification in future studies.

Obesity may also influence sleep apnoea through its inflammatory and metabolic consequences. Centrally-acting proinflammatory cytokines and adipokines such as leptin may alter respiratory control and modulate upper airway function. ${ }^{5} 12$

Table 5 Correlation coefficients for percentage changes $(\% \Delta)$ in facial and abdominal fat volumes measured on CT scan

\begin{tabular}{|c|c|c|c|c|c|c|}
\hline \multirow[b]{3}{*}{ Abdominal fat } & \multicolumn{6}{|c|}{ Facial fat } \\
\hline & \multicolumn{2}{|c|}{$\% \Delta$ Mid-face } & \multicolumn{2}{|c|}{$\% \Delta$ Lower } & \multicolumn{2}{|c|}{$\% \Delta$ Fat pads } \\
\hline & $\bar{R}$ & $\overline{p \text { Value }}$ & $\mathbf{R}$ & p Value & $\mathbf{R}$ & p Value \\
\hline$\% \triangle$ VAT & $0.607^{*}$ & $<0.001$ & $0.493^{*}$ & 0.001 & $0.379^{*}$ & 0.015 \\
\hline$\% \triangle$ SCAT & $0.504^{*}$ & $<0.001$ & $0.477^{*}$ & 0.001 & $0.336^{*}$ & 0.032 \\
\hline
\end{tabular}

${ }^{*}$ Spearman's $\rho$

$\mathrm{R}$, correlation coefficient; SCAT, abdominal subcutaneous adipose tissue; VAT, abdominal visceral adipose tissue.
Indeed, leptin was reduced after the 6-month weight loss programme in patients in this sibutramine-assisted weight loss trial. ${ }^{17}$ Alterations in such factors by changes in adiposity may account for improvement in upper airway neuromuscular control beyond the anatomical changes associated with reductions in mechanical loads on the pharynx and torso. These effects may not directly correlate with measurable fat volumes and may help to account for interindividual variability in changes in AHI with weight loss.

\section{Study limitations}

Several aspects of this study may limit the generalisability of these findings. First, although subjects lost weight, the amount on average was relatively modest (about $7 \%$ of body weight). The corresponding improvement in OSA (about 30\%) appears reasonable for this weight loss, ${ }^{31}$ but greater fat loss may be needed to detect and investigate effects on upper airway structure. Bariatric surgery could therefore be a better paradigm to study the effects of weight on upper airway structure due to the more substantial weight loss achieved.

Sibutramine has a greater effect on reducing central adiposity, ${ }^{32}$ which is more common in men and has a close association with OSA. ${ }^{5}$ Although this is of particular relevance to the population studied, extrapolating these findings to other weight loss methods and women may require caution. Indeed, the influence of regional obesity on the severity of OSA appears to differ between genders, with neck fat in women and abdominal fat in men being of more significance. ${ }^{33}$ This may have implications for weight loss effects on upper airway size, which may be more prominent in women.

Sibutramine, by its action through the central nervous system, may have had some effect on the severity of OSA independent of weight loss, which would affect our assessment of upper airway structure in relation to OSA improvement. However sibutramine, without weight loss, is reported not to affect sleep architecture or OSA severity acutely. ${ }^{34}$

The original experimental design did not include a control group. Comparing 6-month interval CT scans with weight loss may incur variability. Although imaging posture was standardised, fat loss may have led to variations in head or neck posture which may affect airway size and shape. Dental artefact in the oral region also precluded analysis of the entire fat pad structure in some patients. The fat content of specific upper airway soft tissues cannot be as well defined with CT scanning as with MRI. ${ }^{6}$ However, the primary aim of the original study was to investigate the effects of sibutramine-assisted weight loss on OSA, and CT scanning was considered most practical to address the secondary aims of investigating the effects on upper airway structure. Indeed, shorter CT scanning times may be preferable for investigation of the upper airway lumen as the image reflects a single breath hold and is not averaged over 
multiple breath cycles. Also, analysis of large fat volumes-according to the aims of this study-was able to be performed rapidly and CT scanning has been shown to have less inter- and intra-observer variability than MRI. ${ }^{35}$ Also, this study only looked at anatomical changes in the upper airway whereas techniques such as computational fluid dynamics could be used to assess changes in upper airway resistance, which may further explain the improvement in OSA with weight loss. ${ }^{36}$

\section{CONCLUSIONS}

This is the largest study to investigate the effects of weight loss on upper airway structure in OSA using volumetric analysis. Improved OSA in obese men after a 6-month weight loss programme was associated with a small increase in velopharyngeal airway volume mediated by an increase in lateral diameter. Although this volume increase may have contributed to the reduced upper airway collapsibility, decreased upper airway length was found to be most closely associated with AHI reduction. Regional facial fat volumes closely reflect anthropometric variables of body habitus. However, inter-individual variability in the effects of weight loss on OSA severity cannot be explained in terms of changes in upper airway structure and local fat deposition alone. Future phenotyping studies incorporating craniofacial structure, regional body fat distribution, upper airway structure and function, and lung volume are needed to ascertain the relationship between weight loss and improvement in OSA.

Acknowledgements The authors thank Dr Dev Banerjee and Dr Mike Trennell for their contributions to the study.

Funding This study was investigator-driven but was partly funded by Abbott Laboratories, Sydney, Australia (financial support and provision of Sibutramine medication for the participants) and the National Health and Medical Research Council Grant Number 301936.

\section{Competing interests None.}

Ethics approval This study was conducted with the approval of the ethics review committee (Royal Prince Alfred Hospital zone) of the Central Sydney Area Health Service, protocol no. X0203316.

Provenance and peer review Not commissioned; externally peer reviewed.

\section{REFERENCES}

1. Young T, Peppard PE, Taheri S. Excess weight and sleep-disordered breathing. $J$ Appl Physiol 2005;99:1592-9

2. Grunstein RR, Stenlöf K, Hedner JA, et al. Two year reduction in sleep apnea symptoms and associated diabetes incidence after weight loss in severe obesity. Sleep 2007:30:703-10.

3. Johansson $\mathbf{K}$, Neovius M, Lagerros $\mathrm{YT}$, et al. Effect of a very low energy diet on moderate and severe obstructive sleep apnoea in obese men: a randomised controlled trial. BMJ 2009;339:b4609.

4. Yee BJ, Phillips $C L$, Banerjee $D$, et al. The effect of sibutramine-assisted weight loss in men with obstructive sleep apnoea. Int J Obes (Lond) 2007;31:161-8.

5. Schwartz AR, Patil SP, Laffan AM, et al. Obesity and obstructive sleep apnea: pathogenic mechanisms and therapeutic approaches. Proc Am Thorac Soc 2008;5:185-92.

6. Schwab RJ, Pasirstein M, Pierson R, et al. Identification of upper airway anatomic risk factors for obstructive sleep apnea with volumetric magnetic resonance imaging. Am J Respir Crit Care Med 2003;168:522-30.

7. Watanabe T, Isono S, Tanaka A, et al. Contribution of body habitus and craniofacial characteristics to segmental closing pressures of the passive pharynx in patients with sleep-disordered breathing. Am J Respir Crit Care Med 2002;165:260-5.

8. Schwab RJ, Pack Al, Gupta KB, et al. Upper airway and soft tissue structural changes induced by CPAP in normal subjects. Am J Respir Crit Care Med 1996;154:1106-16.
9. Chan AS, Sutherland K, Schwab RJ, et al. The effect of mandibular advancement on upper airway structure in obstructive sleep apnoea. Thorax 2010;65:726-32

10. Hernandez TL, Ballard RD, Weil KM, et al. Effects of maintained weight loss on sleep dynamics and neck morphology in severely obese adults. Obesity (Silver Spring) 2009:17:84-91.

11. Rubinstein I, Colapinto N, Rotstein LE, et al. Improvement in upper airway function after weight loss in patients with obstructive sleep apnea. Am Rev Respir Dis 1988; 138:1192-5.

12. Vgontzas AN. Does obesity play a major role in the pathogenesis of sleep apnoea and its associated manifestations via inflammation, visceral adiposity, and insulin resistance? Arch Physiol Biochem 2008:114:211-23.

13. Levine JA, Ray A, Jensen MD. Relation between chubby cheeks and visceral fat. N Engl J Med 1998;339:1946-7.

14. Sierra-Johnson J, Johnson BD. Facial fat and its relationship to abdominal fat: a marker for insulin resistance? Med Hypotheses 2004;63:783-6.

15. Lee RW, Sutherland K, Chan AS, et al. Relationship between surface facial dimensions and upper airway structures in obstructive sleep apnea. Sleep 2010;33:1249-54.

16. Lee RW, Petocz P, Prvan T, et al. Prediction of obstructive sleep apnea with craniofacial photographic analysis. Sleep 2009;32:46-52.

17. Phillips CL, Yee BJ, Trenell MI, et al. Changes in regional adiposity and cardiometabolic function following a weight loss program with sibutramine in obese men with obstructive sleep apnea. J Clin Sleep Med 2009;5:416-21.

18. Barkdull GC, Kohl CA, Patel $\mathrm{M}$, et al. Computed tomography imaging of patients with obstructive sleep apnea. Laryngoscope 2008;118:1486-92.

19. Welch KC, Foster GD, Ritter CT, et al. A novel volumetric magnetic resonance imaging paradigm to study upper airway anatomy. Sleep 2002;25:532-42

20. Abramson Z, Susarla S, August M, et al. Three-dimensional computed tomographic analysis of airway anatomy in patients with obstructive sleep apnea. J Oral Maxillofac Surg 2010;68:354-62

21. Malhotra A, Huang $\mathrm{Y}$, Fogel RB, et al. The male predisposition to pharyngeal collapse: importance of airway length. Am J Respir Crit Care Med 2002;166:1388-95.

22. Pae EK, Lowe AA, Fleetham JA. A role of pharyngeal length in obstructive sleep apnea patients. Am J Orthod Dentofacial Orthop 1997;111:12-17.

23. Owens RL, Malhotra A, Eckert DJ, et al. The influence of end-expiratory lung volume on measurements of pharyngeal collapsibility. J Appl Physiol 2010;108:445-51.

24. Burger CD, Stanson AW, Daniels BK, et al. Fast-CT evaluation of the effect of lung volume on upper airway size and function in normal men. Am Rev Respir Dis 1992;146:335-9

25. Hoffstein V, Zamel N, Phillipson EA. Lung volume dependence of pharyngeal cross-sectional area in patients with obstructive sleep apnea. Am Rev Respir Dis 1984:130:175-8.

26. Schwartz AR, Patil SP, Squier S, et al. Obesity and upper airway control during sleep. J Appl Physiol 2010;108:430-5.

27. Johal A, Patel SI, Battagel JM. The relationship between craniofacial anatomy and obstructive sleep apnoea: a case-controlled study. J Sleep Res 2007:16:319-26

28. Hora F, Nápolis LM, Daltro C, et al. Clinical, anthropometric and upper airway anatomic characteristics of obese patients with obstructive sleep apnea syndrome. Respiration 2007; 74:517-24

29. Schäfer $\mathbf{H}$, Pauleit D, Sudhop T, et al. Body fat distribution, serum leptin, and cardiovascular risk factors in men with obstructive sleep apnea. Chest 2002;122:829-39.

30. Tsuiki S, Isono S, Ishikawa $T$, et al. Anatomical balance of the upper airway and obstructive sleep apnea. Anesthesiology 2008;108:1009-15

31. Peppard PE, Young T, Palta M, et al. Longitudinal study of moderate weight change and sleep-disordered breathing. JAMA 2000:284:3015-21.

32. Kamel EG, McNeill G, Van Wijk MC. Change in intra-abdominal adipose tissue volume during weight loss in obese men and women: correlation between magnetic resonance imaging and anthropometric measurements. Int J Obes Relat Metab Disord 2000;24:607-13.

33. Simpson L, Mukherjee S, Cooper MN, et al. Sex differences in the association of regional fat distribution with the severity of obstructive sleep apnea. Sleep 2010;33:467-74

34. Martinez D, Basile BR. Sibutramine does not worsen sleep apnea syndrome: a randomized double-blind placebo-controlled study. Sleep Med 2005;6:467-70.

35. Yoon DY, Moon JH, Kim HK, et al. Comparison of low-dose CT and MR for measurement of intra-abdominal adipose tissue: a phantom and human study. Acad Radiol 2008;15:62-70.

36. Vos W, De Backer J, Devolder A, et al. Correlation between severity of sleep apnea and upper airway morphology based on advanced anatomical and functional imaging. J Biomech 2010;40:2207-13. 